\title{
JARINGAN KOMPUTER DARI JARAK JAUH DENGAN PENERAPAN HAMACHI VPN
}

\author{
Fahlepi Roma Doni \\ Universitas Bina Sarana Informatika \\ fahlepi.fro@bsi.ac.id
}

\begin{abstract}
With the advancement of the development of the times, then the technology also develops, especially the application technology that shows rapid progress, ifrastruktur field of communication that can support for the creation of systems or applications that are reliable also experienced rapid development. The technology used so that we can control a computer from a different network place or region by using a hamachi VPN (Virtual Private Network) application, using this application then we are as if it will be in one computer network and we can control the computer from other places, the coverage that we can access is not limited to regions, different places, islands, countries and even different continents can be interconnected. The development of different computer technology area every day is also growing and the coverage is wider, not only in one coverage area only, even can become global coverage (the world), that is using internet, with this internet facility, hence to use computer network from Different areas of places can be affordable with hamachi VPN applications can even reach a large area.
\end{abstract}

\section{Keywords: Information technology, Hamachi VPN, Internet}

Abstrak - Dengan semakin majunya berkembangan zaman, maka teknologi ikut berkembang juga, khususnya teknologi aplikasi yang menunjukkan kemajuan yang sangat pesat, ifrastruktur dibidang komunikasi yang bisa mendukung untuk terciptanya sistem atau aplikasi yang handal ikut mengalami perkembangan pesat juga. Teknologi yang digunakan supaya kita bisa mengendalikan komputer dari jaringan yang berbeda tempat atau wilayah dengan menggunakan sebuah aplikasi hamachi VPN (Virtual Private Network), dengan menggunakan aplikasi ini maka kita seolah-olah akan berada dalan satu jaringan komputer dan kita bisa mengendalikan komputer dari tempat lain, cakupan yang dapat kita akses itu tidak terbatas wilayah, berbeda tempat, pulau, negara bahkan yang berbeda benua bisa saling terkoneksi. Perkembangan teknologi jaringan komputer yang berbeda area setiap harinya juga semakin berkembang dan cakupan semakin luas, tidak hanya dalam satu cakupan area saja, bahkan bisa menjadi cakupan global (dunia), yakni menggunakan internet, dengan adanya fasilitas internet ini, maka untuk menggunakan jaringan komputer dari area yang berbeda tempat bisa terjangkau dengan aplikasi hamachi VPN bahkan bisa menjangkau wilayah yang luas.

Kata kunci : Teknologi informasi, Hamachi VPN, Internet

\section{A. PENDAHULUAN}

Dari penelitian sebelumnya bahwa penggunaan jaringan komputer hanya terbatas local area network saja (LAN). Kalau untuk akses jaringan komputer dari jarak jauh atau yang berbeda area wilayah harus berlanggaan IP Publik kepada internet service provider (ISP) dan biasanya untuk biaya bulanannya juga cukup mahal.

Dengan menggunakan aplikasi hamachi VPN (Virtual Private Network) ini kita tidak perlu berlanggaan IP Publik dan tidak perlu mengeluarkan biaya yang cukup besar setiap bulannya. Karena dengan menggunakan hamachi VPN ini kita sudah mendapatkan IP Publik secara gratis dan dapat dipergunakan untuk segala keperluan didalam jaringan komputer.
Dan semakin majunya perkembangan teknologi informasi, baik teknolgi dibidang prangkat keras maupun dibidang perangkat lunak, khususnya untuk perkembangan teknologi dibidang perangkat lunak, penulis akan meneliti dan menganalisa bagaimana cara terbaik dalam penerapan untuk jaringan komputer dari area yang berbeda, yang bisa menjangkau cakupan yang global atau mendunia, tanpa terhalang lagi oleh jarak yang jauh, misalkan yang berbeda pulau bahkan berbeda benua bisa saling terhubung dengan memanfaatkan hamachi VPN dan menggunakan media internet.

Penelitian penerapan ini dilakukan bertujuan untuk :

1. Penggunaan hamachi VPN untuk jaringan komputer dari area atau wilayah yang berbeda, juga bisa kita kendalikan melalui 
hamachi VPN, jadi tidak terbatas menggunakan jaringan local saja.

2. Untuk mengetahui penyebab atau faktor apa saja yang mempengaruhi penggunaan hamachi VPN.

3. Untuk mengetahui bagaimana model atau metode penggunaan hamachi VPN.

4. Memberikan saran atau masukan untuk pengguna hamachi VPN.

\section{B. TINJAUAN PUSTAKA}

1. Jaringan Komputer

(Doni, 2014) "Jaringan komputer adalah kumpulan komputer saling terhubung dan membentuk suatu kesatuan system". Pertukaran data yang berpindah dari satu jaringan ke yang lain.

(Kadir \& Triwahyuni, 2013) Bentuk atau jenis jaringan komputer berdasarkan area kerja dibedakan menjadi beberapa kelompok, yaitu : LAN (Local Area Network), MAN (Metropolitan Area Network), WAN (Wide Area Network)

\section{Topologi}

(Doni \& Lesmono, 2018) Topologi dalam jaringan mengandung dua pengertian dilihat dari sisi pengkabelan dan dari sisi aliran data".

\section{Internet}

(Doni \& Lesmono, 2018) internet adalah gabungan dari berbagai LAN dan WAN yang berada di seluruh jaringan komputer di dunia, sehingga terbentuk jaringan skala yang lebih luas dan global.

(Doni \& Lesmono, 2018) Internet diartikan sebagai "The global public Transmission Control Protocol/Internet Protocol (TCP/IP) internetwork".

\section{Akses jaringan komputer jarak jauh}

(Ikhsan, 2014) Akses komputer jarak jauh (remote access) sering dianggap melakukan tindakan illegal. Karena banyak disalah gunakan untuk proses pencurian data dan sebagainya disebut cracker. cracker sifatya cenderung lebih merusak system tersebut.

(Ikhsan, 2014) adapun fungsi jaringan komputer jarak jauh yang bersifat Global.
a. Mengendalikan PC lain dari lokasi yang berbeda.
b. Mematikan PC dari tempat yang berbeda
c. Merestart PC lain
d. Mengawasi penggunaan PC lain
e. Membantu pengguna lain
f. Mengawasi penggunaan PC lain
g. Pemeliharaan PC lain
h. Berbagi data.

Gambar dibawah ini topologi penelitian sebelumnya, dimana akses jaringam komputer hanya LAN saja.

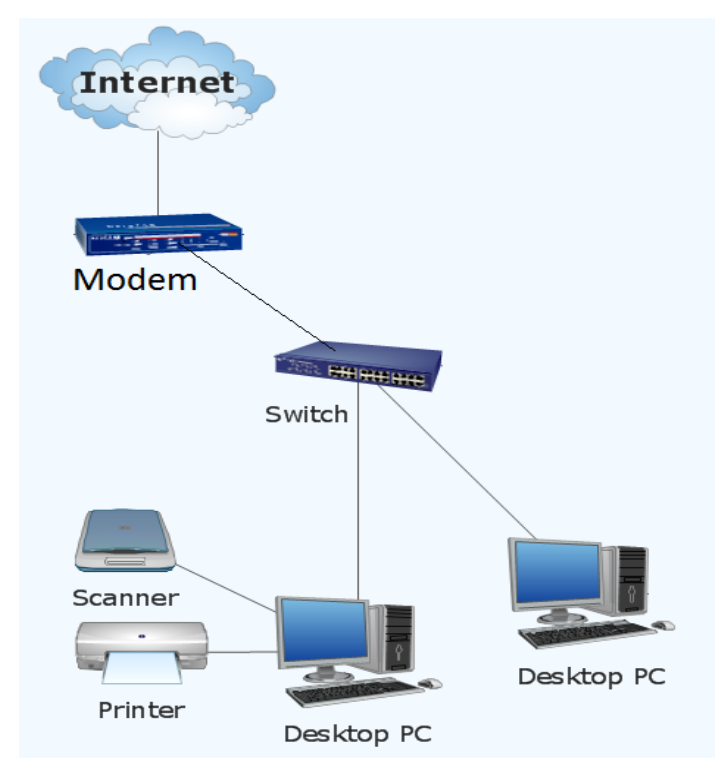

\section{Gambar 1. Topologi penelitian sebelumnya}

\section{METODE PENELITIAN}

Metode yang penulis gunakan yaitu dengan merencanakan penelitian penerapan seperti halnya penelitian (research) pada umumnya, dalam merencanakan penelitian penerapan ini.

(Triyono \& Dharma, 2018) menyarankan langkah-langkah dalam sebuah perencanaan penerapan meliputi :

1. Mengidentifikasi masalah

2. Merumuskan masalah

3. Menganalisis masalah dan merumuskan tindakan

4. Membuat rencana

5. Melaksanakan tindakan

6. Mengamatinya

7. Mengolah

8. Menafsirkan data penerapan

9. Melaporkan hasil penerapan.

(Stringer, 2007) Meskipun demikian ada beberapa tahapan bisa dilalui dalam penerapan yaitu : tahap perencanaan (planning), tahap pelaksanaan (acting), pengamatan (observation), dan refleksi (reflection).

(Stringer, 2007) Kemudian keempat langkah tersebut dikemukakan oleh Lewin diatas, oleh Stringer dielaborasi menjadi tiga langkah saja yakni:
1. Perencanaan (planning)
2. Pelaksanaan (implementing)
3. Penilaian (evaluation) 


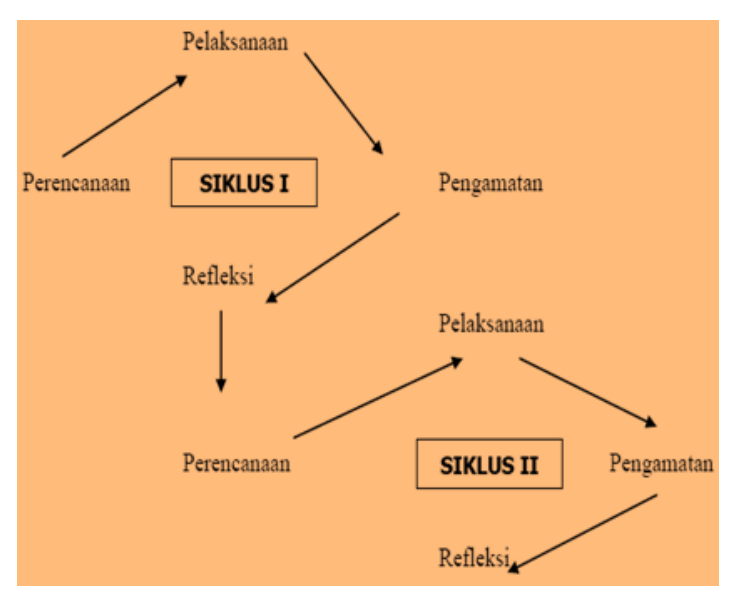

Gambar 2. Model Alur Penelitian Penerapan

Untuk aplikasi jaringan komputer disini penulis menggunakan aplikasi hamachi VPN (Virtual Private Network) dan akan dijelaskan bagaimana caranya menginstal aplikasi hamachi VPN ini. Cara menginstalnya cukup mudah, dan tidak memerlukan waktu lama, namun sebelumnya jika kita hendak menginstal di komputer, kita harus mempuyai instalan aplikasi tersebut.

\section{Cara instal setup hamachi VPN :}

Prosedur untuk server

1. Jalankan setup program, dan instal hamach

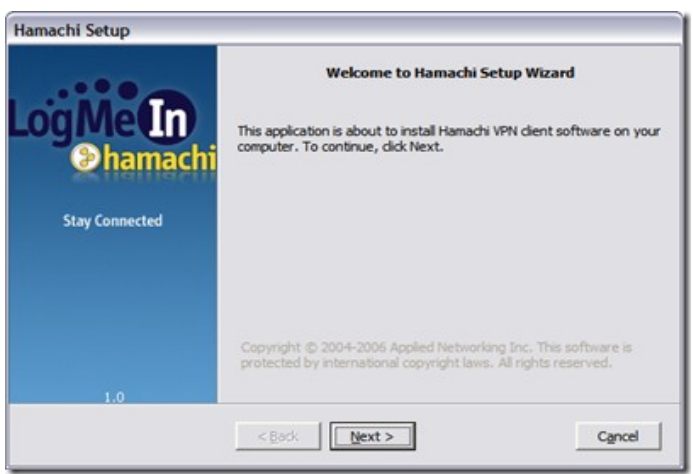

Gambar 3. Instalasi hamachi VPN

2. Tunggu proses instalasi sampai selesai

\section{HASIL DAN PEMBAHASAN}

Pada penelitian penerapan ini penulis menambahkan media akses jarangan komputer bisa bisa diakses dari mana saja, baik beda wilaya atau berbeda pulau maupun beda benua

Dengan hamachi bisa mengakses jaringan komputer dimana saja, tanpa harus berlanggaan IP Publik kepada ISP. Jadi dengan penerapan hamachi dapat menghemat biaya.

Gambar berikut merupakan topologi penelitian yang akan penulis terapkan.

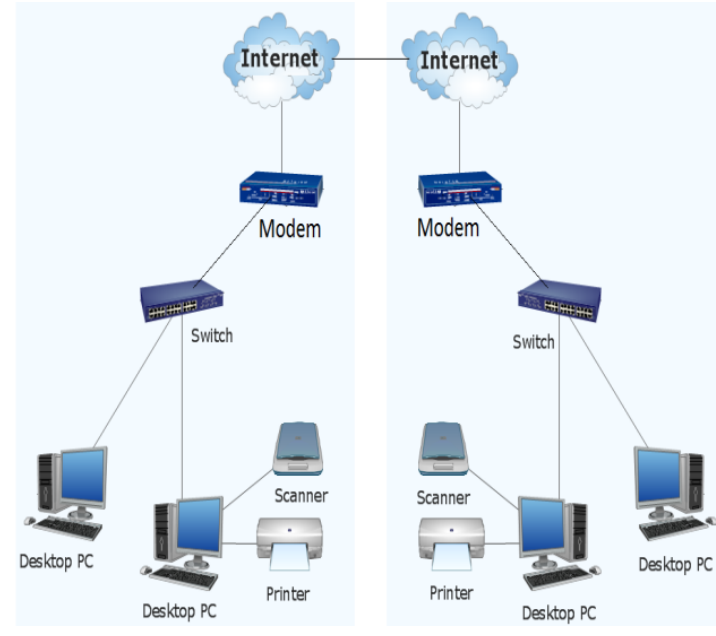

\section{Gambar 4. Topologi penelitian yang diterapkan}

Secara umum tahapan-tahapan untuk penerapan ini, yang penulis gunakan di gambar dibawah ini

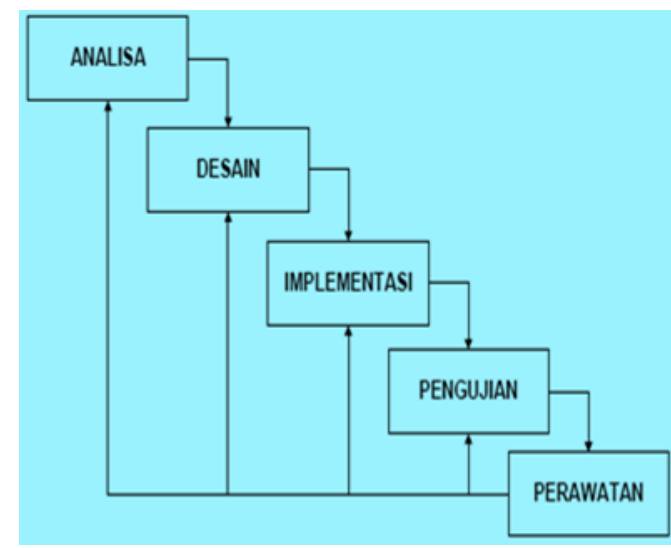

\section{Gambar 5. Tahapan-tahapan untuk penerapan remote akses}

\section{Cara mengoperasikan Hamachi VPN :}

1. Jalankan hamachi VPN, klik Power on. Assign.

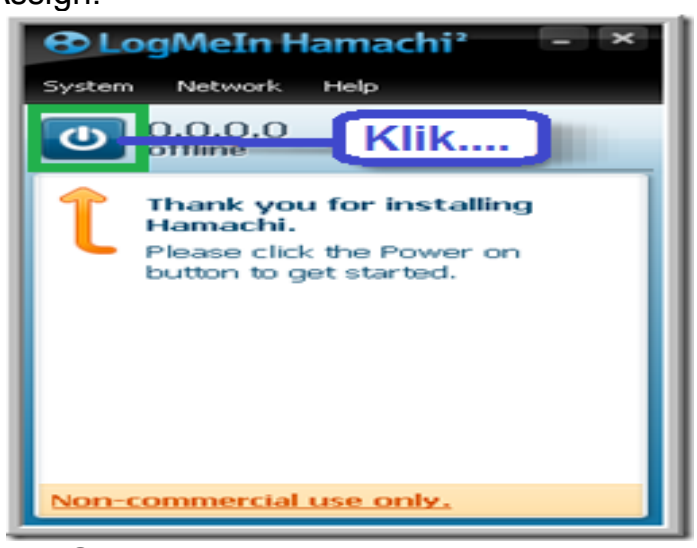

Gambar 5. Tampilan Hamachi VPN 
2. Klik create a new network untuk membuat network di komputer utama (server).

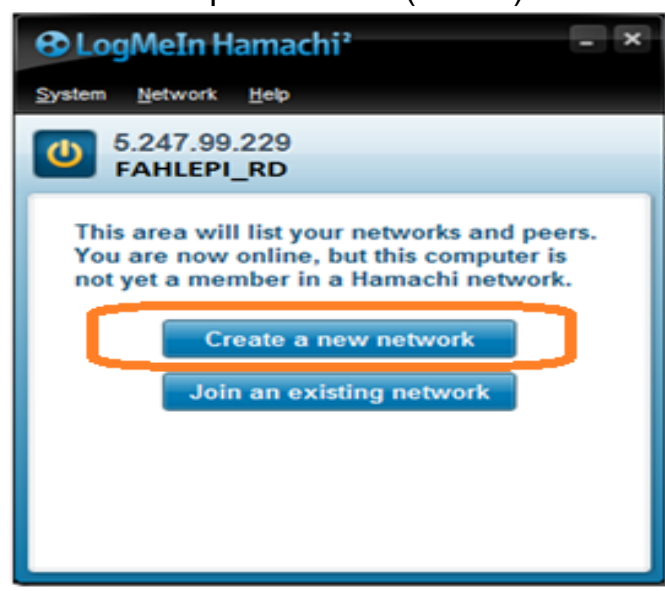

Gambar 6. Membuat Network Hamachi VPN

3. Masukan nama network dan password, untuk menambah anggota ke dalam network.

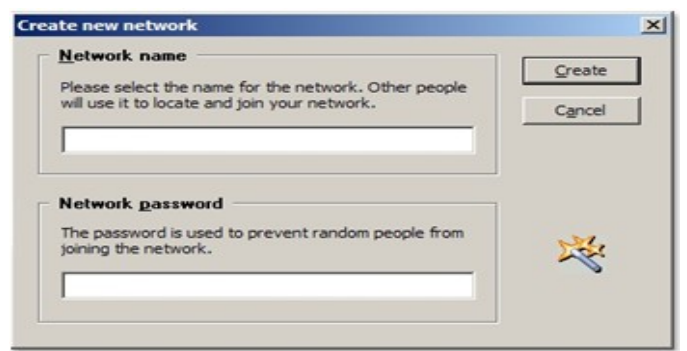

Gambar 7. Membuat password untuk menambahkan anggota

4. Network selesai dibuat.

Prosedur untuk instalasi pada komputer client :

1. Install hamachi VPN di

2. Lakukan power on hamachi dan setup hostname

3. Lalu klik join existing network

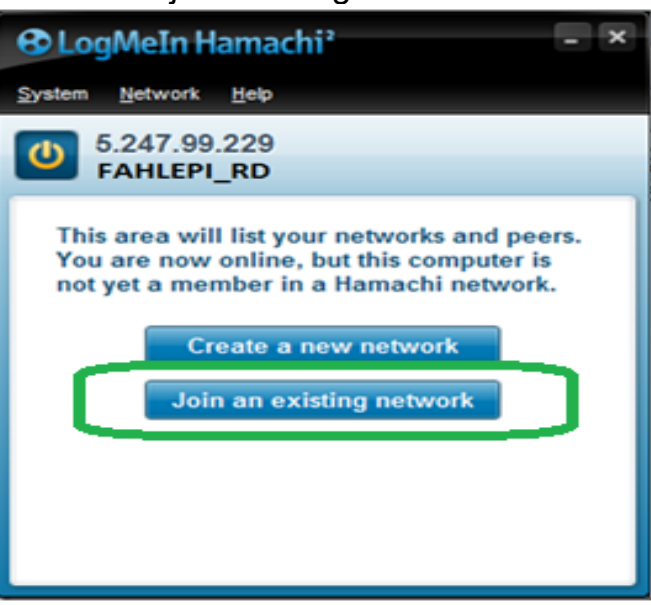

Gambar 8. Join Jaringan Hamachi VPN

4. Isi network id dan password untuk server

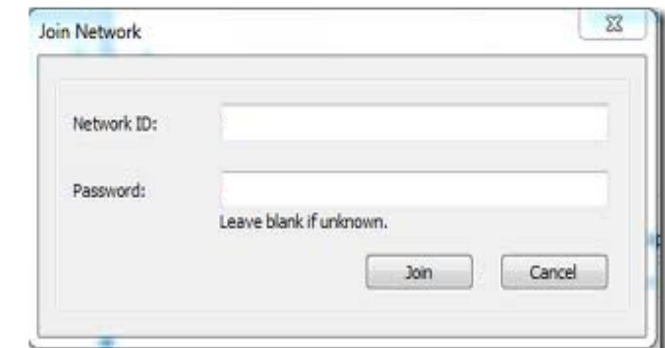

Gambar 9. Input Password untuk Jaringan Hamachi VPN

5. Lakukan approve di server untuk menghubungkan client dengan network

6. Tampilan Hamachi VPN yang sudah terhubung dengan komputer lain.

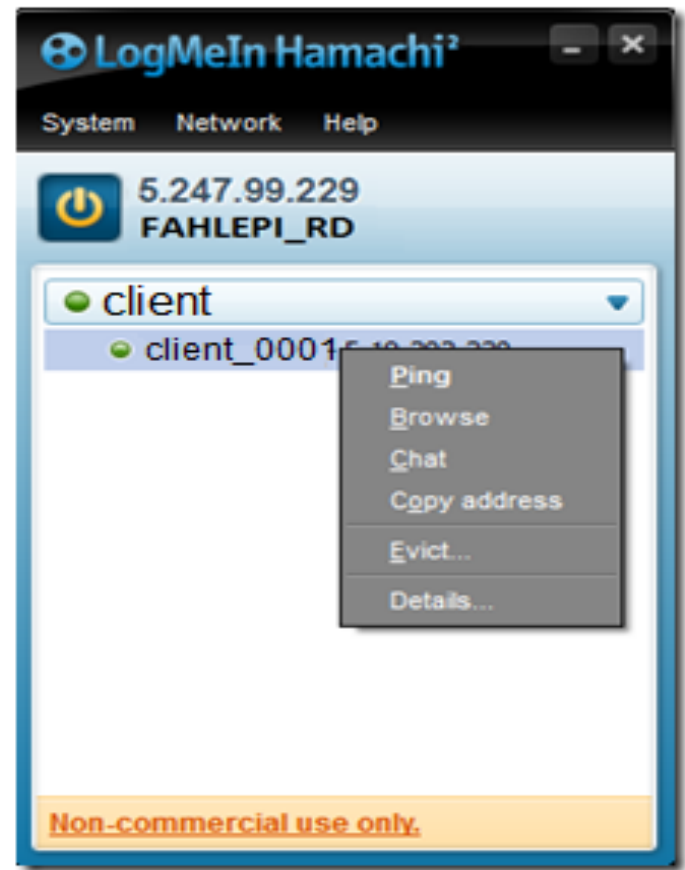

Gambar 10. Jaringan Hamachi VPN

7. Ulangi cara diatas tersebut, untuk setiap penambahan client didalam jaringan hamachi VPN

\section{Fungsi Hamachi VPN}

Dari hasil proses pengujian diatas, maka dapat dianalisa bahwa fungsi utama dari hamachi VPN adalah untuk membuat atau merancang suatu jaringan komputer yang bisa diakses darimana saja tanpa harus berlangan IP Publik

\section{Keunggulan dan Manfaat Hamachi VPN :}

1. Tergolong fleksibel, Komputer seolah-olah berada di dalam network LAN atau WAN.

2. Bisa digunakan di banyak operating system 
3. Setup yang tergolong simpel

4. Bisa dikoneksi dengan LogMeln account

5. Bisa menggunakan topologi network dan managed mode

6. Bisa melakukan chat dengan komputer lain

\section{E. KESIMPULAN}

Pada penelitian ini penulis menggunakan aplikasi hamachi VPN adalah untuk membuat atau merancang suatu jaringan komputer yang bisa kita akses darimana saja tanpa harus berlangan IP Publik dan kita tidak perlu mengeluarkan biaya bulanan yang cukup besar untuk menyewa IP Publik kepada kepada penyedia layanan yaitu internet service provider (ISP)

Setelah penulis melakukan analisa pada penerapan penggunaan hamachi VPN untuk jaringan komputer yang bisa diakses darimana, maka dapat disimpulkan :

1. Dari penelitian sebelumnya bahwa penggunaan IP Publik harus berlanganan kepada ISP.

2. Kemudian didalam penelitian ini penulis menerapkan penggunaan hamachi VPN untuk jaringan PC bisa diakses dari wilayah yang berbeda, tanpa harus berlagangan kepada ISP kita bisa mendapatkan IP Publik.

3. Media internet mampu menjadi penghubung jaringan komputerjarak jauh, terutama yang dilakukan di area yang berbeda.

4. Dengan memanfaatkan aplikasi hamachi VPN mampu bekerja sebagai control pc dan control akses penuh dalam proses peremotan dengan perantara media internet, sehingga kendala pc yang terjadi didaerah yang berbeda, dapat diakses menggunakan aplikasi hamachi VPN.

5. Hamachi VPN ada fitur khusus untuk penggunanya sehingga proses terjadinya kontrol pc lain dan akses dalam proses peremotan yang dilakukan, karena fasilitas yang disediakan yaitu, transfer file dan fitur chating.

Selain beberapa kesimpulan, ada beberapa saran yaitu:

1. Pengguna sebaiknya selalu memperbaharuhi aplikasinya.

2. Apabilah hendak menggunakan aplikasi hamachi VPN diharapkan melakukan pemeliharan atau perawatan secara berkala, demi kelancaran dalam proses akses jaringan komputer.

3. Untuk meningkatkan kinerja sebaiknya fasilitas yang dirasakan kurang baik kinerja perangkatnya, maka hendaknya dilakukan upgrade secara berkala, agar dapat mendukung terciptanya suatu sistem yang handal.

\section{DAFTAR PUSTAKA}

Doni, F. R. (2014). Optimalisasi Jaringan Wireless Dengan Router Mikrotik Studi Kasus Kampus Bsi Tangerang. Evolusi, II(1), 37-45.

Doni, F. R., \& Lesmono, I. D. (2018). Mengubah Jarak dengan Penerapan Remote Access Menggunakan Team Viewer, 18(2), 129-136.

Ikhsan. (2014). Pengendalian PC Jarak Jauh dengan Memanfaatkan Media Internet. Teknoif, 2(1).

Kadir, A., \& Triwahyuni, T. (2013). Pengantar Teknologi Informasi Edisi Revisi. https://doi.org/10.13140/2.1.4734.7840

Stringer, E. (2007). Action Research 3rd. ed. Action Research.

Triyono, T., \& Dharma, U. W. (2018). Penelitian Tindakan Kelas: Apa Dan Bagaimana Melaksanakannya?, (March), 1-17.

https://doi.org/10.13140/RG.2.2.26385.12 649 